\title{
A GENERALIZATION OF SOME FIXED POINT THEOREMS OF K.M. GHOSH
}

\author{
B.E. RHOADES \\ Mathematics Department \\ Indiana University \\ Bloomington, Indiana 47405 \\ (Received April 10, 1981)
}

ABSTRACT. This note establishes the following result. Let $T$ be a selfmap of a normed linear space E. For $0<\lambda \leq 1$, define $\mathrm{T}_{\lambda} \mathrm{x}=\lambda \mathrm{x}+(1-\lambda) \mathrm{Tx}$ for each $\mathrm{x}$ in $\mathrm{E}$. If, In addition, $\mathrm{S}=\mathrm{TT}_{\lambda}$ satisfies any contractive definition strong enough to guarantee that $S$ has a unique fixed point $u$ in $E$, and, if $\mathrm{TT}_{\lambda} \mathrm{u}=\mathrm{T}_{\lambda} \mathrm{Tu}$, then $\mathrm{u}$ is the unique fixed point for $T$.

KEY WORDS AND PHRASES. Fixed Point, Mean Value Iteration. 1980 MATHEMATICS SUBJECT CLASSIFICATION CODES. Primary 47 H10.

1. INTRODUCTION.

The purpose of this note is to formalize the underlying principle in Theorems 1 and 4 of [1].

To prove the result stated in the abstract, observe that $\mathrm{T}\left(\mathrm{T}_{\lambda} \mathrm{Tu}\right)=\mathrm{T}\left(\mathrm{TT}_{\lambda} \mathrm{u}\right)=$ $\mathrm{Tu}$. Hence $\mathrm{Tu}$ is also a fixed point of $\mathrm{S}=\operatorname{TT}_{\lambda}$. Since the fixed point of $\mathrm{S}$ is unique, $\mathrm{u}=\mathrm{Tu}$.

For uniqueness, since the fixed point set for $T_{\lambda}, F\left(T_{\lambda}\right)$, contains $F(T)$, with equality when $\lambda \neq 1$, it is clear that $F\left(\mathrm{TT}_{\lambda}\right) \supset \mathrm{F}(\mathrm{T})$.

Example 4 of [1], corrected to $\mathrm{read} \mathrm{Tx}=1$ for $\mathrm{x} \in[0,1), \mathrm{T}(1)=0$, shows that the condition $\mathrm{TT}_{\lambda} \mathrm{u}=\mathrm{T} \mathrm{Tu}$ is necessary.

REFERENCE

1. GHOSH, M.K. A generalization of contraction principle, Inter. J. Math. \& Math. Sci. 4 (1981) 201-206. 


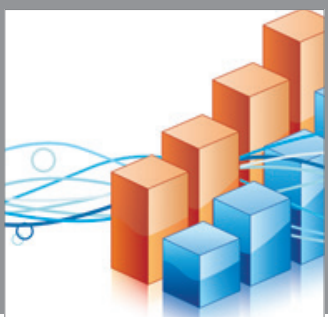

Advances in

Operations Research

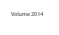

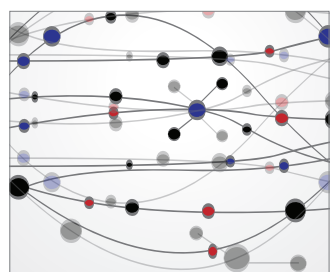

\section{The Scientific} World Journal
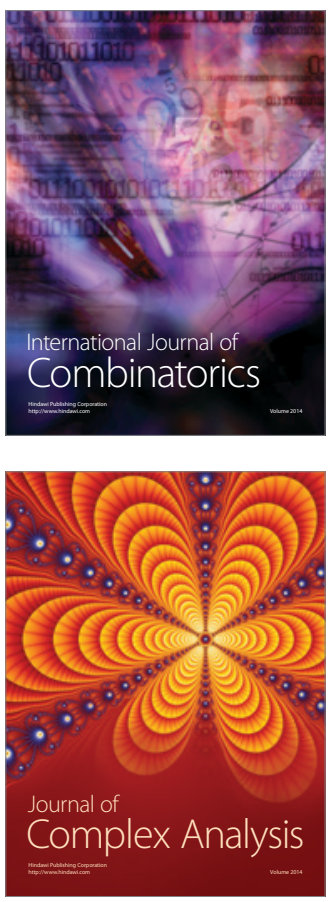

International Journal of

Mathematics and

Mathematical

Sciences
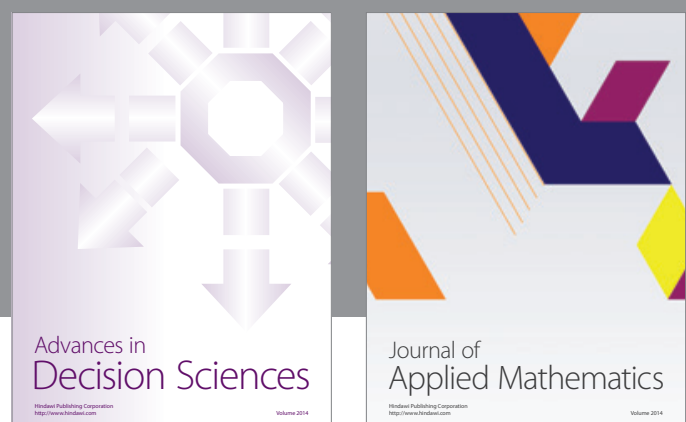

Journal of

Applied Mathematics
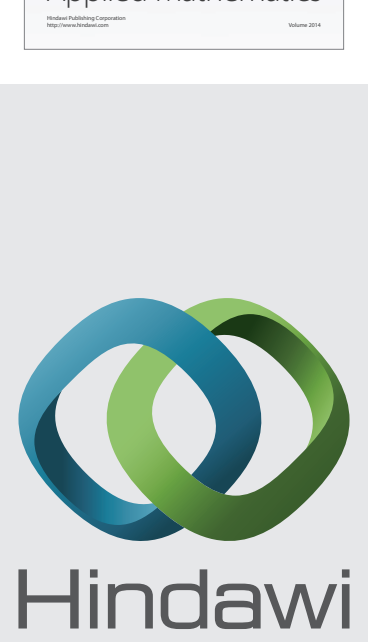

Submit your manuscripts at http://www.hindawi.com
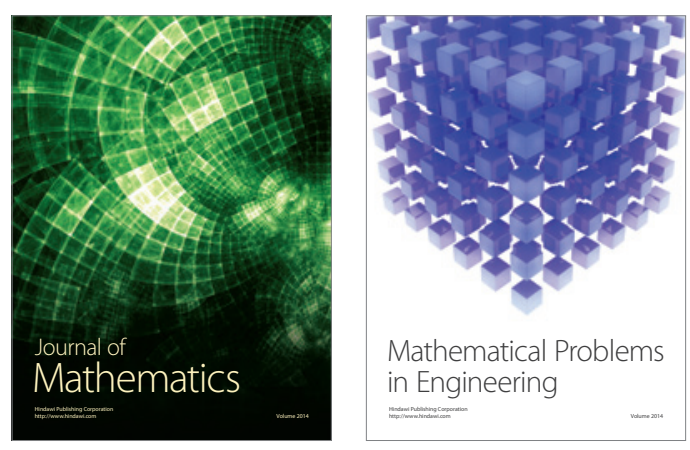

Mathematical Problems in Engineering
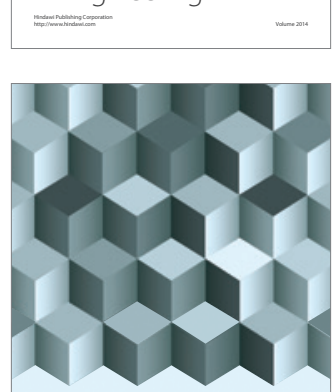

Journal of

Function Spaces
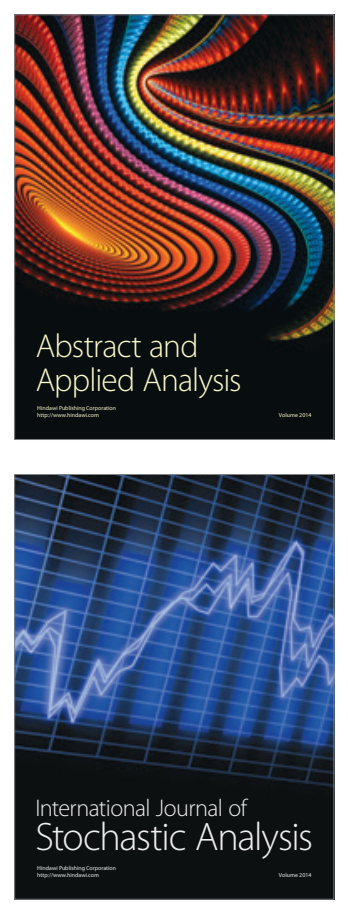

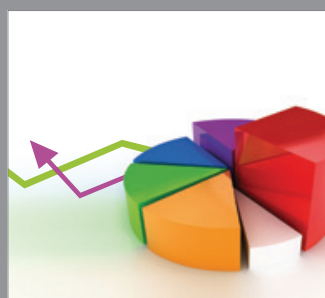

ournal of

Probability and Statistics

Promensencen
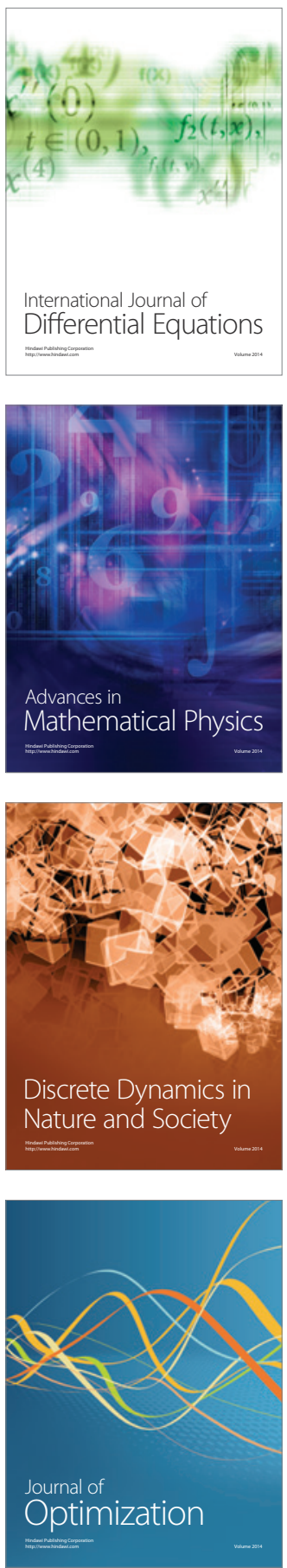